lectures on astronomy, he so excited the public interest that the necessary funds were supplied for erecting an observatory at Harvard. A remarkable series of lectures on "Ideality in Science," delivered by him in I879 before the Lowell Institute in Boston, attracted the general attention of American thinkers, on account of the thoughtful consideration of the vexed question of science and religion.

Much of Prof. Peirce's activity was absorbed by his duties as the head of the American Coast Survey, a position in which he succeeded Prof. Bache. He brought to this work the same degree of zeal and ability which were so brilliantly evidenced by his predecessor, and constantly maintained the well-earned reputation of the Coast Survey among the hydrographic efforts of our day. Prof. Peirce was one of the founders of the American National Academy of Sciences. In I853 he presided over the American Association for the Advancement of Science. The degree of LL.D. was conferred upon him twice, by the University of North Carolina (1847), and by Harvard University (1867). He was elected an Associate of the Royal Astronomical Society (1849), and a Fellow of the Royal Society of London (1852), and of the Royal Societies of Edinburgh and Göttingen.

Prof. Peirce leaves behind him his wife, a daughter, and three sons. Of the latter one is Professor of Mathematics at Harvard, and another is Professor at Johns Hopkins University.

\section{RECENT CHEMICAL RESEARCH}

THE masses of facts accumulated in the text-books on 1 chemistry are already portentous: each month, almost each week, adds to the store.

The difficulty of getting a stable standing-ground from which to survey, in order, if possible, to find the meaning of these facts, increases likewise.

Fortunately from time to time there are found investigators who, turning from the easy toil of adding new compounds to those which are as yet but imperfectly known, concern themsclves with the fundamental questions of chemical science.

Why are the properties of bodies so largely modified under certain conditions? This is the all-important question for the chemist. Before this question can be answered for a series of substances the properties of those substances must be accurately known, and the variations in their properties under varying conditions-themselves definitely ascertained-must be determined. Among the properties of substances thọse which we usually call physical are, as a rule, more susceptible of accurate measurement than those which we call chemical.

But these physical properties must be connected in some way with the chemical structure of the little parts, or molecules, of which we conceive the substances to be built up.

To determine what this connection is in the case of a definite physical property, and for a series of chemical substances, is at present one of the most promising problems which presents itself to the chemical inquirer.

But these physico-chemical problems require for their solution, a practical knowledge both of chemical and physical methods; methods of laboratory work and methods of reasoning on the results obtained. Students of nature trained in both methods are not extremely abundant.

The suggestion made in the prefacc to Armstrong and Grove's new volume on Organic Chemistry, that eacl chemical school should regularly prepare special series of pure compounds, and should let it be known that physical observers can procure these compounds in order to determine their physical properties, is well worthy of being acted on by all in whose hands may rest the arrangement of the work of any chemical school.
The older method of regarding chemical physics as consisting of a little chemistry loosely tacked on to a great deal of ordinary physics, is disappearing; and chemists and physicists now recognise that the problems which each attacks are, in very many instances, but different aspects of the same question.

The more thoroughly the chemical worker is trained in the correct use of dynamical principles and dynamical reasoning, the more likely is he to succeed in his search for chemical truth.

Very recently two papers have appeared, the contents of which illustrate the importance of the results obtainable by physico-chemical methods.

Brubl has published in Liebig's Annalen-and in a condensed form in the Berlin Berichte-the results of his investigations on the connection between physical properties and chemical constitution of carbon compounds; and Thomsen, in the Journal fiir practische Chemie (and also in the Berichte) has given the first two instalments of his thermal work bearing on the isomerism of carbon compounds.

I propose to give a short account of the work of these two chemists : let us begin with Thomsen's.

The "heat of formation" of a compound substance is the difference between the sum of the heats of combustion of the constituent elements of the compound, and the heat of combustion of the compound itself. But this heat is not the true "heat of formation" of the molecule of the compound; it is only the algebraic sum of various heat disturbances. The thermal change which accompanies the formation of a compound molecule from various elementary molecules consists of various parts: (I) heat absorbed in dissociating the molecules of the different elements; (2) in some cases, heat absorbed in liquefying or gasefying the constituent elements; (3) heat evolved in the formation, from the dissociated elementary atoms, of the new compound molecules; and (4) in some cases heat evolved in the liquefaction or solidification of the gaseous compound molecules. If the physical state of the various substances concerned be constant throughout the experiment, (2) and (4) may be ncglected; and the heat of formation will be equal to the difference between the heat absorbed in splitting the elementary molecules, and that evolved in the falling together of the atoms so produced, in the new configuration. The value of the first part of this operation will always be constant for the same element or elements; but the value of the second part will depend upon the configuration assumed by the elementary atoms in the new compound molecules.

Now the generally accepted chemical theory of isomerism is that it (isomerism) is dependent on varying configuration of the same atoms. Some chemists have urged that isomerism is more probably due to the possession, by the different compounds, of different amounts of energy. But these two theories are really parts of the same theory. Thomsen's method, indeed, may be said to be based on this fundamental identity.

Given the dissociated elementary atoms, they may arrange themselves in various ways, each arrangement will be attended with a definite but different evolution of heat, hence, inasmuch as the heat absorbed in the preliminary clemental dissociation is fixed, the heats of formation of the various isomeric molecules will be different.

But when it is said that isomerism depends on atomic configuration, two things are included in this statement. Lct us consider isomerism in a hydrocarbon : the carbon atom combines with four, and not more than four, hydrogen atoms to form a compound molecule. The carbon atom is said to be tetravalent ; this is usually graphically expressed by the symbol $=\mathrm{C}=$. The maximum number of hydrogen atoms which two carbon atoms can combine with to form a definite molecule will be six, 
and the molecule will be graphically represented as . But we also know of a compound the molecule of which contains two carbon, but only four hydrogen atoms, this is represented as $\stackrel{\mathrm{H}}{\mathrm{H}}>\mathrm{C}=\mathrm{C}\left\langle\mathrm{H}_{\mathrm{H}}^{\mathrm{H}}\right.$, and a third hydrocarbon, $\mathrm{C}_{2} \mathrm{H}_{2}$, is represented as $\mathrm{H}-\mathrm{C} \equiv \mathrm{C}-\mathrm{H}$. In the first molecule the carbon atoms are commonly said to be "singly-linked," in the second "doubly-linked," and in the third "trebly-linked." We do not as yet attach any definite physical conception to these phrases; a compound said to contain "singly-linked" carbon atoms is, as a fact, incapable of combining with hydrogen or other monovalent element, whilst a compound said to contain "doubly-linked" carbon atoms can combine with two monovalent atoms for each pair of doubly-linked carbon atoms it is represented as containing; and a compound said to contain "trebly-linked" carbon atoms is capable of combining with four monovalent atoms for each pair of trebly-linked carbon atoms in the graphic formula thereof.

These are instances of isomerism said to be due to differences in the linking of the atoms of the isomeric molecules. But according to the generally accepted theory isomerism may arise among hydrocarbons in which all the carbon atoms are singly-linked; such isomerism is due to different relative arrangements of parts of the molecule. We may suppose all the carbon atoms arranged in a chain, or we may suppose ramifications of these atoms; thus the hydrocarbons represented as<smiles>CCC</smiles><smiles>CC1CC1</smiles>

would be

isomeric.

Thomsen deals only with isomerism due to differences in the linking of atoms. If from a certain number of dissociated carbon and hydrogen atoms a compound be produced containing only "singly-linked" carbon atoms, that compound is not capable of taking up any more hydrogen; but if a compound be produced containing "doubly-linked" carbon atoms, that compound is capable of taking up more hydrogen. But in the act of combining with more hydrogen, heat will be evolved; hence the heat of formation of the first compound is greater than that of the second. The heat of formation of an isomeric compound containing "trebly.linked" carbon atoms would be less than that of either of the preceding.

Thomsen, from the results of his own and other experiments, has calculated the heat of formation, from amorphous carbon, of a pair of singly-linked, a pair of doubly-linked, a pair of trebly-linked, and a pair of quadruply-linked carbon atoms. From these values he has calculated the heats of formation of isomers containing singly, doubly, or trebly-linked carbon atoms. The calculations involve certain assumptions, but the applications of his results to actual hydrocarbons show very close agreement between the calculated and the actually determined "heats of formation."

Thomsen furnishes us with a thermal value for the formation of each of the three possible linkings of the group $\mathrm{C}_{2}$ in the molecule of compounds. The value of this result to the chemist is great; a determination of the heat of combustion of a hydrocarbon may now yield him much information as to the structure of the molecule of that hydrocarbon.

Thomsen's results also strengthen the commonly- accepted theory of isomerism, and they point towards a dynamical explanation of this theory and to the possibility of attaching a definite physical idea to the phrases "singly" or "doubly-linked" atoms.

As Thomsen has succeeded in tracing a quantitative connection between the heats of formation of certain molecules containing carbon and the linking of the carbon atoms in these molecules, so Brühl has shown that the linking of carbon atoms exerts a definite, measureable influence on the molecular refractions of compounds of this element.

Landolt showed many years ago, that in many compounds, the atoms of each elementary substance, possessed a definite specific refractive capacity independently of the way in which the atoms might be grouped.

Molecular refraction is defined as $\left(\frac{\mu-I}{d}\right)$. M, where $\mu=$ refractive index, $d=$ density of substance, and $M=$ molecular weight.

The difference between the molecular refraction of a compound containing carbon, hydrogen, and oxygen, and that of a compound containing the same number of carbon and hydrogen atoms, but free from oxygen, gave the atomic refraction of oxygen. Numbers were thus found expressing the atomic refraction of carbon, hydrogen, oxygen, and a few other elements. Gladstone and Dale showed, however, that the observed molecular refractions of many carbon compounds, especially the compounds existing in essential oils, were greater than the refractions calculated from Landolt's numbers : it seemed that the grouping of atoms did exert, in certain cases, an influence on the refractive power of molecules.

Briihl finds that certain groups of isomeric carbon compounds possess but one molecular refraction; in these groups the refractive power of the molecules is independent of the grouping of the atoms; in other isomeric groups, however, the molecular refraction varies. The members of the latter groups of isomers are always represented in structural formulæ as containing "doublylinked" carbon atoms. Now if the molecular refraction be conditioned by the linking, but not by the grouping, of the atoms in the molecule, it follows that the atomic refraction of each monovalent element must be a constant number, inasmuch as there is but one way of linking a monovalent atom to other atoms. Such isomers as ethylene chloride, $\mathrm{ClH}_{2} \mathrm{C}-\mathrm{CH}_{2} \mathrm{Cl}$, and ethylidene chloride, $\mathrm{Cl}_{2} \mathrm{HC}-\mathrm{CH}_{3}$, should possess the same molecular refraction. But the atomic refraction of any polyvalent atom, e.g. oxygen, must vary according as the atom is linked by one, two, or more "bonds" to other atoms: such isomers

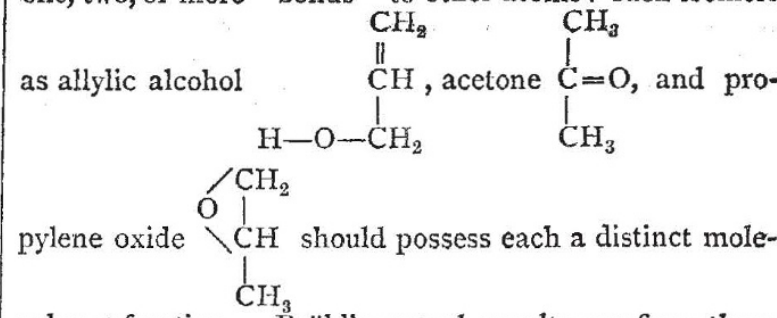
cular refraction. Brühl's actual results confirm these deductions. There is then a definite value for the atomic refraction of the carbon, or oxygen, atom according as that atom is "singly-linked" or "doubly-linked" to other atoms: in other words, the molecular refraction of a compound containing the group $-\mathrm{C}-\mathrm{C}-$ is different from that of the isomer containing the group $>\mathrm{C}=\mathrm{C}_{<}^{\prime}$; and the molecular refraction of a compound containing the group $\mathrm{C}=\mathrm{O}$ is different from that of the isomer 
containing the group $\backslash \mathrm{C}-\mathrm{O}-$. Brühl obtains a definite numerical value for the refractive power of each of these groups.

Now although the molecular refraction of isomers with similarly linked, but differently grouped, carbon or oxygen atoms is constant, the refractive indices and the densities of these isomers are not the same. There is, therefore, a definite connection between the densities and refractive indices of carbon compounds, and the grouping, as distinguished from the linking, of the atoms in these compounds. The densities and refractive indices of the isomers, ethylene chloride and ethylidene chloride (see ante) are not the same. Bruihl has not determined any exact numerical value for the refractive power of this or that grouping of carbon or other atoms; generally, however, he has shown that the more ramifications there are in the structural formula of a carbon compound, the smaller is the density and the smaller the refractive index of that compound. Thus the density of butylic iodide, $\mathrm{CH}_{3}-\mathrm{CH}_{2}-\mathrm{CH}_{2}-\mathrm{CH}_{2} \mathrm{I}$, is $\mathrm{I} \cdot 6166$, and the refractive index $(\mu)$ is $1.4960 \mathrm{I}$; but the density of the

isomeric isobutylic iodide, $\mathrm{CH}_{3}-\mathrm{CH}-\mathrm{CH}_{3}$

and the refractive inclex is $1 \cdot 49192$.

$$
\stackrel{\mathrm{CH}}{2} \mathrm{I}^{\mathrm{I}} \text {, is } \mathrm{I} \cdot 6056 \text {, }
$$

Generally, then, it would appear that when rays of light pass through a series of isomeric carbon compounds, the isomerism of which is traceable only to differences in the grouping of the constituent atoms, then that ray which passes through the densest compound is more bent from its original course than any of the other rays; but that when isomerism is due to differences in the linking of the atoms, then the amount to which the rays are bent is dependent not only on the density, but also on the molecular "structure" of the compounds.

Briihl considers also the connection existing between the boiling points, and other physical constants, of isomeric carbon compounds containing only singly-linked polyvalent atoms, i.e. compounds the isomerism of which is due only to variations in the grouping of the atoms, and the structural formulx of these compounds. His results establish a considerable probability in favour of the rule, that in such isomeric groups, those compounds which have the smallest molecular volumes, have also the highest boiling points, greatest specific gravities and refractive indices (not greatest molecular refraction), and longest time of flow through capillary tubes; and very probably these compounds have also the smallest amount of ramification in their molecular structure.

Brïhl thus put into the hand of the chemist another means whereby he may readily learn much concerning the inner structure of the substances which he examines. Brühl's results, as also those of Thomsen, exhibit a close connection between physical properties of compounds and the valency, or specific saturation power, of the elementary atoms which build up these compounds.

As the theories of modern chemistry are so largely based on the idea of valency, the results of Bruihl and Thomsen are most welcome, as at once tending to confirm the general soundness of the methods of the Newcr Chemistry, and exhibiting at least two measurable physical phenomena as closely connected with the exercise of valency.

The results of both obscrvers emphasise the difference which chemists have long recognised between two kinds of isomerism : that due to "grouping," and that due to "linking" of atoms. Is it not at least possible, in view of these results, that a greater part of the chemical energy of molecules containing doubly (or trebly) linked polyvalent atoms is kinetic, than is the case in isomeric molecules, the atoms of which are all singly-linked? if indeed the chemical energy of the latter molecules be not wholly potential. Double-linking might then mean greater kinetic energy ; and the entropy of a molecule containing only singly-linked atoms would be greater than that of its isomer, some of the atoms in which were doubly-linked.

The consideration of valency of atoms is closely connected with the more general subject of chemical affinity; and the work of Thomsen and Brühl suggests many questions connected with affinity which press for answers.

A short account was given in this journal (vol. $\mathrm{xx}$. p. 530) of the work of Culdberg and Waage, and of Ostwald, on chemical affinity. The lattcr naturalist has recently extended his methods of observation: in his earlier papers he used physical methods, determining the changes in the specific volumes, and also in the refractive indices, of solutions of acids and bases when these acted chemically on each other, and hence calculating the amount of chemical action. Ostwald now employs a more purely chemical method; he allows acids of known strength to react on a solid salt in excess, and determines the amount of action at definite intervals. His results, so far as they have extended, ${ }^{1}$ strikingly confirm the numbers which he before obtained for the relative affinities of the commoner acids.

The application of the theory of Guldberg and Waage to reactions between a solid and a liquid, the former being in excess, requires that a definite and stable condition of equilibrium should be reached at the expiry of not too great a time. Doubt was thrown on Ostwald's results because it was said that such equilibrium had not been attained. In his latest paper Ostwald has carefully examined this point, and has shown that the required equilibrium is attaincd, and maintained, and that therefore such reactions are well suited for the study of general problems of affinity. Ostwald's future results, as he extends the application of the chemical method, will doubtless be very interesting.

All the work which has been here shortly noticed tells unmistakably that chemistry is rapidly passing out of the natural history stage of progress into that stage where her facts will be accurately grouped under general laws, which laws will admit of quantitative statement, and of quantitative deductions being made from them.

The recent work in chemistry also illustrates the need of a wide training in the methods of various sciences for the investigator of this branch of natural phenomena. One man begins with a purely chemical investigation, another with one which appears wholly physical ; before long they find that their paths meet, and that the problem which each had attacked without thought of the other, can be solved, and even then solved but partially, only by the united effort of both.

M. M. PATtison MuiR

\section{$J A P A N^{2}$}

\section{I.}

MR. MURRAY is to be congratulated on being able M to bring out simultaneously two such excellent books on a country which for some years has probably attracted more interest than any other country in the world. Although they both treat of the same subject, they differ much in their method of treatment. Indeed the one may be said to be complementary of the other; and any one who reads them both with care will be able to form a very complete idea of the present condition of an unusually interesting country and people. Sir Edward Reed went out practically as the guest of the Japanese Government, and had ample opportunities of seeing the

I His papers are in the Founal fiur practische: Chemie of the last and present year.

2 "Japan: its History, Traditions, and Religions, with the Narrative of a Visit in $x 879$," By Sir Edward J. Reed, K.C.B., F.R.S., M.P. Two vols. With Map and Illustrations. (London: John Murray, ${ }^{1880}$.) "Unbeaten Tracks in Japan." By Isabella L. Burd. Two vols. With Map and Illustrations. (Same Publisher.) 